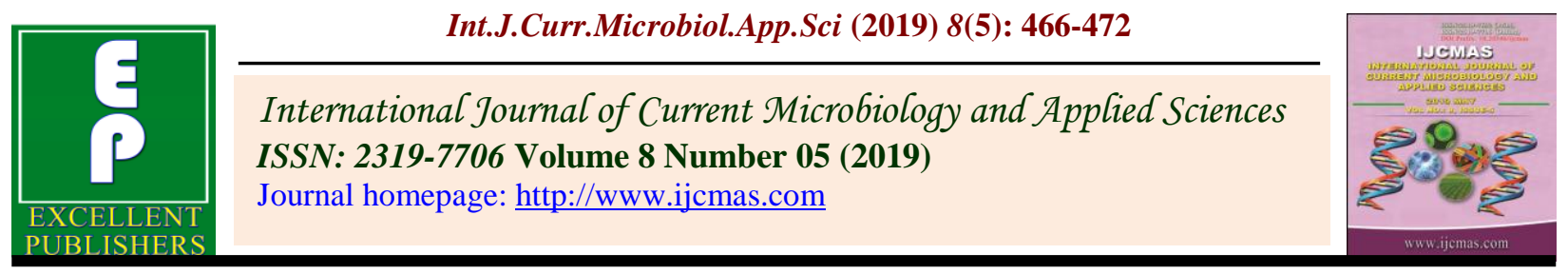

Original Research Article https://doi.org/10.20546/ijcmas.2019.805.055

\title{
Quality Evaluation of Osmosed Jackfruit Bulb Slices
}

\author{
K. Mithun ${ }^{1 *}$ and S. Kaleemullah ${ }^{2}$ \\ ${ }^{1}$ Dr. NTR College of Agricultural Engineering, ANGRAU, Bapatla, India \\ ${ }^{2}$ PHET Center, RARS, ANGRAU, Tirupati, India \\ *Corresponding author
}

\section{A B S T R A C T}

\begin{tabular}{|c|}
\hline Keywords \\
\hline $\begin{array}{l}\text { Jackfruit bulb } \\
\text { slices, Osmotic } \\
\text { dewatering, Quality } \\
\text { evaluation }\end{array}$ \\
\hline Article Info \\
\hline $\begin{array}{l}\text { Accepted: } \\
04 \text { April } 2019 \\
\text { Available Online: } \\
10 \text { May } 2019\end{array}$ \\
\hline
\end{tabular}

\section{Introduction}

Jackfruit (Artocarpus heterophyllus L.) the largest tree-borne fruit, is a native of South and Southeast Asia. India, Bangladesh, and Thailand are the largest producers of jackfruit in the global village. India is the global leader in jackfruit production in the global village. Jackfruit, popularly known as "poor man's fruit" is the most under-utilized fruit. The largest jackfruit producing states in the country are Tripura, Odisha, Assam, West Bengal, Chhattisgarh, Jharkhand, Madhya Pradesh, Tamil Nadu, Andhra Pradesh, Kerala, Telangana, Karnataka. Jackfruit is the national fruit of Bangladesh and Kerala has declared it as its state fruit (George, 2018).
The area under cultivation and production of jackfruit in India is 1,87,000 ha and 18,57,000 MT for the year 2018-2019 (Indiast at, 2019). Jackfruit is available round the year in Panruti of Tamil Nadu, Idukki district of Kerala and Tumku rof Karnataka (Down To Earth, 2018).

According to the UN Food and Agricultural Organization, $75 \%$ of the jackfruit produced in India, gets spoiled due to the lack of proper processing facilities (Worldatlas, 2017). The jackfruit produced during peak season if processed fetches revenue to the farmers by selling them in the glut season. Thus the development of value added products from jackfruit have become inevitable. 
Osmotic dewatering process is the novel food processing operation to dehydrate the fruits, vegetables and meat products. Osmotic dewatering process is a partial water removal process. The osmotic dewatering process aids in reduced weight of the product, reduction in the consumable space during transportation, increased shelf life and a retained quality of the product (Sahu et al., 2017). The water loss and the solid gain are the two important mass transfer operations generally occur in the osmotic dehydrated process. Thus osmotic dewatering process has added advantages over general drying of jackfruit.

In India, majority of the food processing industries engages osmotic dehydration technique to remove moisture from fruits and vegetables because osmotic dehydration methods retains the flavour, colour, texture and shelf-life of processed product (Sutar and Gupta, 2007).

Osmotic dehydration is generally used as a pre-treatment by many food processors prior to freezing, freeze drying, vacuum drying and air drying (Nanjundaswamy et al., 1978). The rate of transfer of water from material to the solution depends upon several factors such as solution concentration, temperature, shape and size of the material and method of agitation.

Therefore an attempt was made to determine the quality of osmotic dewatered jack fruit bulb slices. The quality parameters were determined at the optimized condition of osmotic dewatering process. Thus, the osmotic dewatered jackfruit bulb slices quality was compared to that of the fresh one.

\section{Materials and Methods}

\section{Raw material}

Matured jackfruits, obtained from local market were washed in running water to eliminate dirt or dust adhered to it. The jackfruits were cut manually using a SS knife and the bulbs were separated manually without the application of any edible oil. The seeds were parted from the bulb manually by vertical slitting using a knife. The bulbs were cut into uniform square shape $(2 \times 2 \mathrm{~cm})$ slices with average thickness of $4.5 \mathrm{~mm}$.

\section{Physico-chemical analysis}

Moisture content of fresh jackfruit bulb slices was determined by AOAC (2005). Total soluble solids (TSS) were measured by hand refractometer (Atago, Tokyo) by grinding the slices in mortar with pestle. The $\mathrm{pH}$ and titratable acidity of fresh fruit were determined by the methods given by Ranganna (1986). Sampling was done in triplicate.

\section{Preparation of osmotic solution}

Commercial sugar was used as solute in the osmotic solution. The osmotic solution of contributed are $60{ }^{\circ} \mathrm{B}$ at a temperature of 57 ${ }^{\circ} \mathrm{C}$ and immerged for $160 \mathrm{~min}$. Preservatives like citric acid $(0.3 \% \mathrm{w} / \mathrm{v}$, food grade) and potassium metabisulfite $(1 \% \mathrm{w} / \mathrm{v}$, food grade) were added to the osmotic solution. Experiments were conducted at fruit to solution ratio of 1:4.

\section{Osmotic dewatering process}

Twenty five grams of jackfruit bulb slices were immerged in osmotic solution contained in stainless steel container. The container is kept in thermostat-controlled oven. The movement of water and sugar was analysed by calculating water loss (WL) and solid gain (SG). After osmotic dehydration process, the jackfruit slices were taken out of the solution, rubbed gently with muslin cloth to remove the adhered solute on their surfaces and were weighed immediately. The slices were 
weighed and moisture content was determined by using vacuum oven (AOAC 2005).

\section{Hardness}

The hardness of the fresh and osmotic dewatered samples was determined by Texture analyser (Brookfield Engineering Labs, Inc., USA) compression tests. It was equipped with $12.7 \mathrm{~mm}$ dia. stainless steel ball probe (TA18) (Fig. 1) operated at pre-test speed of $1 \mathrm{~mm} \mathrm{~s}^{-1}$, test speed and post-test of $0.5 \mathrm{~mm} \mathrm{~s}^{-1}$. Load cell of $5 \mathrm{~kg}$ was used to fracture the slice.

\section{Colour}

Colour of fresh and treated slices was measured using Hunter Lab Color Flex spectrophotometer (Hunter Lab Associates Laboratory, USA). The measurement was done with an illuminate observer combination of $\mathrm{D} 65 / 10^{\circ}$. The surface colour was quantified in terms of $\mathrm{L}^{*}, \mathrm{a}^{*}$ and $\mathrm{b}^{*}$ values of CIELAB colour space. The CIELAB colour space is organised in a cube form, where $\mathrm{L}^{*}$ axis runs from top to bottom with minimum value of 0 , representing black and maximum of 100 representing white. The axis $-\mathrm{a}^{*},+\mathrm{a}^{*}$ goes from green to red and the $a x i s-b^{*},+b^{*}$ goes from blue to yellow. The samples were placed over the port. The instrument was standardised with white and black ceramic tiles before starting the measurement. The colour of sample was measured by measuring $\mathrm{L}^{*}, \mathrm{a}^{*}$ and $\mathrm{b}^{*}$ values. The total colour difference is calculated by below given equation,

$\Delta E=\sqrt{\left(\left(L-b^{8}\right)^{2}+\left(a-a^{8}\right)^{2}+\left(b-b^{8}\right)^{2}\right)}$

where,

$\mathrm{L}, \mathrm{a}, \mathrm{b}=$ chromaticity values for fresh jackfruit bulb slice
$\mathrm{L}^{*}, \mathrm{a}^{*}, \mathrm{~b}^{*}=$ chromaticity values for treated fruit jackfruit bulb slice

\section{Ascorbic acid content}

Ascorbic acid content (Fig. 2) of the samples was determined by the method described by AOAC (2005).

\section{Sensory evaluation}

Sensory evaluation of samples was carried out for consumer acceptance and preference using 10 untrained panelists selected at random. Appearance, flavour, overall acceptability of the samples were rated using a 9-point Hedonic scale (Beckley et al., 2012).

Sensory evaluation was carried out at ambient conditions in a comfortable and quiet area without disturbance under fluorescent lighting. Water was supplied to cleanse palate between samples. Four sensory attributes stated below were considered for the study (Table 1).

\section{Results and Discussion}

\section{Physio-chemical analysis}

The total soluble solids (TSS), $\mathrm{pH}$ and titratable acidity of fresh jackfruit bulb slices were recorded as $28{ }^{\circ} \mathrm{B}, 5.2$ and 2.4 , respectively. The initial moisture content of the jackfruit bulb slices was recorded around $200 \%$ (d.b.). Moisture content of jackfruit bulb slices after osmotic dehydration was around $100 \%$ (d.b.).

The values pertaining to the quality parameters were represented in the Table 2 . Hardness, yellow chromaticity, total colour difference, ascorbic acid content, appearance, odour, taste, overall acceptability of fresh and osmotic dewatered jackfruit bulb slices were tabulated. 
Table.1 Score card for sensory attributes during sensory evaluation

\begin{tabular}{|c|c|c|}
\hline Sensory attributes & Opinion & Score \\
\hline \multirow{2}{*}{ Appearance } & Like extremely & 9 \\
\cline { 2 - 3 } & Like very much & 8 \\
\hline \multirow{2}{*}{ Odour } & Like moderately & 7 \\
\hline \multirow{2}{*}{ Taste } & Like slightly & 6 \\
\hline \multirow{2}{*}{ Overall } & Neither like nor dislike & 5 \\
\hline \multirow{2}{*}{ acceptability } & Dislike slightly & 4 \\
\hline & Dislike moderately & 3 \\
\hline & Dislike very much & 2 \\
\hline
\end{tabular}

(Source: Beckley et al., 2012)

Table.2 Score values for quality parameters of fresh and osmotic dewatered jackfruit bulb slices

\begin{tabular}{|l|c|c|}
\hline \multicolumn{1}{|c|}{ Quality parameter } & Fresh sample & Osmotic dewatered sample \\
\hline Hardness $(\mathbf{N})$ & $37 \pm 1$ & $50 \pm 1$ \\
\hline Yellow chromaticity $\left(\mathbf{b}^{*}\right)$ & $48.60 \pm 1.33$ & $49.69 \pm 5.48$ \\
\hline Total colour difference $(\mathbf{\Delta E )}$ & - & $2.86 \pm 4.15$ \\
\hline $\begin{array}{l}\text { Ascorbic acid content } \mathbf{( m g / 1 0 0} \\
\text { g) }\end{array}$ & $9.82 \pm 0.18$ & $5.56 \pm 0.51$ \\
\hline Appearance & $7.2 \pm 0.6$ & $6.9 \pm 0.9$ \\
\hline Odour & $8.1 \pm 0.7$ & $8.0 \pm 1.1$ \\
\hline Taste & $6.6 \pm 0.7$ & $8.0 \pm 0.9$ \\
\hline Overall acceptability & $6.8 \pm 1.0$ & $7.0 \pm 0.8$ \\
\hline
\end{tabular}

Fig.1 SS ball probe fitted to texture analyzer

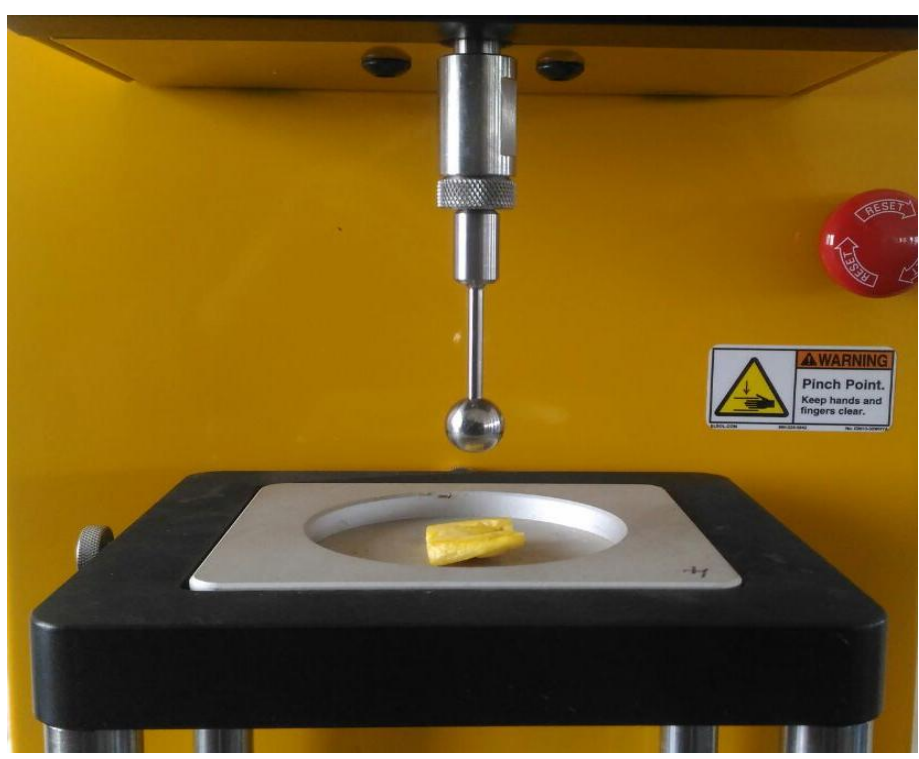


Fig.2 Flow chart for estimation of ascorbic acid

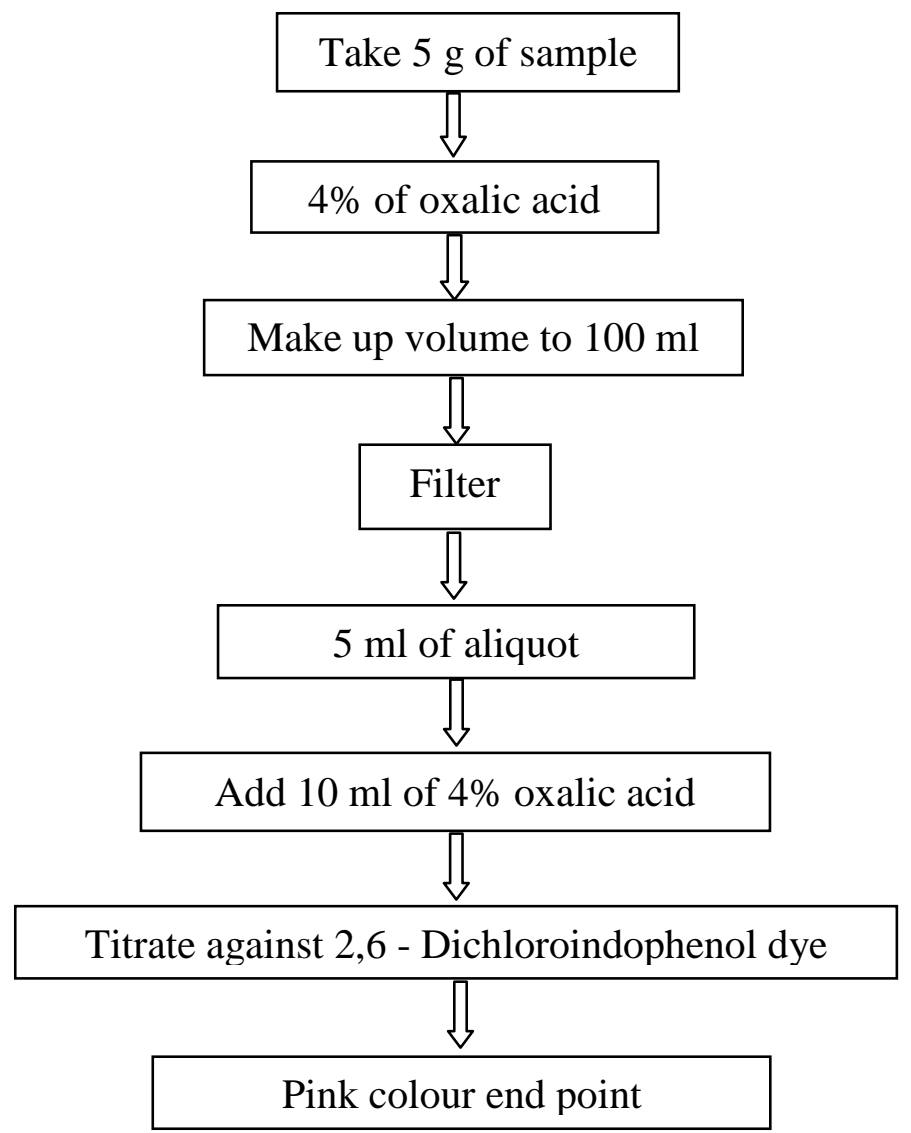

\section{Hardness}

The hardness of the fresh jackfruit bulb slices and osmotic dewatered sample were $37 \pm 1$ and $50 \pm 1$ respectively. The increase in the hardness might be due to the diffusion of sugar into the jackfruit slice, which made it firm in texture. Similar results were drawn by Knezevic et al., (2013) in case of pork meat.

\section{Colour}

The yellow chromaticity $\left(b^{*}\right)$ values for fresh and osmotic dehydrated jackfruit bulb slices were $48.60 \pm 1.33$ and $49.69 \pm 5.48$ respectively. The improvement in yellow colour might be due to the reason that the sugar on heating contributes creamy yellow appearance. The layer of sugar coated on jackfruit bulb slices, during the diffusion process, might have helped in colour enhancement. These results are in agreement with strawberries (GarciaNoguera et al., 2014)

\section{Ascorbic acid content}

The ascorbic acid content of fresh and osmotic dehydrated jackfruit bulb slices were $9.82 \pm 0.18$ and $5.56 \pm 0.51$ respectively. This clearly indicates that the osmotic dewatering process aids in ascorbic acid loss during diffusion process. Similar results were observed in case of pears (Nadia et al., 2013) and majority of the fruits and vegetables (Santos and Silva, 2008).

\section{Sensory evaluation}

The appearance, taste, odour and overall acceptability of fresh and osmotic dehydrated 
jackfruit bulb slices were $7.2 \pm 0.6,6.6 \pm 0.7$, $8.1 \pm 0.7, \quad 6.8 \pm 1.0$ and $6.9 \pm 0.9, \quad 8.0 \pm 0.9$, $8.0 \pm 1.1,7.0 \pm 0.8$ respectively. The increase in taste perception is due to the increased sugar content during solid gain phenomena of osmotic dewatering process. There is slight improvement in appearance, this might be due to the yellow colour of the sugar solution. There is no change in odour, because, the jackfruit has strong fragrance. The overall acceptability of osmotic dewatered jackfruit bulb slices is greater when compared to fresh jackfruit bulb slices. The odour and taste quality perceptions are in agreement with Azoubel et al., (2009) in the case of cashew apple, but the appearance perception is contradictory with the present investigations.

In conclusion, the osmotic dewatering process has shown significant effect on the quality of jackfruit bulb slices. The quality parameters like hardness, ascorbic acid content, colour, appearance, taste, odour and overall acceptability were determined. The osmotic dewatering process showed positive effect on the hardness, colour, appearance, taste and negative effect on ascorbic acid content. The overall acceptability of the osmotic dewatered jackfruit bulb slices was recorded high. Thus the osmotic dewatering process aids in a superior quality product. Thus osmotic dewatering or osmotic dehydration technique can be adopted on wide variety of perishable foods.

\section{Acknowledgement}

The authors acknowledge the endorsement received in the form of procurement of material, equipment, facilities provided by Acharya N.G. Ranga Agricultural University.

\section{References}

AOAC., 2005. Official methods of analysis. 18th ed. Association of Official Analytical Chemists, USA.
Azoubel, PM., El-Aouar AA, Tonon RV, Kurozawa LE, Antonio GC, Murr FEX and Park KJ. 2009. Effect of osmotic dehydration on the drying kinetics and quality of cashew apple International Journal of Food Science and Technology. 44: 980-986

Beckley, J., Paredes D and Lopetcharat K. 2012. Product Innovation Tool Box: A Field Guide to Consumer Understanding and Research. WileyBlackwell, USA.

Down To Earth. 2018. The jackfruit will definitely become the most soughtafter fruit in the coming years in India. (Accessed 21 ${ }^{\text {st }}$ March 2019)

https://www.downtoearth.org.in/interviews/fo od/-the-jackfruit-will-definitelybecome-the-most-sought-after-fruitin-the-coming-years-in-india--50450

Garcia-Noguera J., Oliveira FIP, Weller CL, Rodrigues $\mathrm{S}$ and Fernandes FAN. 2014. Effect of ultrasonic and osmotic dehydration pre-treatments on the colour of freeze dried strawberries. Journal of Food Science and Technology. $\quad 51(9)$ : 22222227.doi: 10.1007/s13197-012-0724-x

George, MPJ., 2018. The jackfruit board bill. Bill No. 153 of 2018. (Accessed 21 ${ }^{\text {st }}$ March 2019). http://164.100.47.4/ billstexts/lsbilltexts/asintroduced/1833 LS\%20AS\%20INTRO.pdf

Indiastat. 2019. Area and production of jackfruit in India ( $1^{\text {st }}$ Advance Estimates). (Accessed $2^{\text {nd }}$ April 2019)

Knezevic, V., Curcic B, Filipovic V, Nicetin $\mathrm{M}$, Levic L, Kuljanin T and Gubic J. 2013. Influence of osmotic dehydration on colour and texture of pork meat. Journal on Processing and Energy in Agriculture. 17(1): 38-42

Nadia, DM., Nourhène BM, Nabil K, Francis C and Catherine B. 2013. Effect of Osmo-dehydration Conditions on the Quality Attributes of Pears. J Food 
Process Technol 4:256. doi: 10.4172/2157-7110.1000256

PHS Santos and MA Silva. 2008. Retention of Vitamin C in Drying Processes of Fruits and Vegetables-A Review. Drying Technology 26(12): 1421-1437

Ranganna, S., 1986. Handbook of Analysis and Quality Control for Fruit and Vegetable Products. $2^{\text {nd }}$ Ed. Tata McGraw-Hill, New Delhi.

Sahu, G., Vinoda N, Monisha P, Paradkar V and Kumar N. 2017. Studies on drying of osmotically dehydrated onion slices. Int. J. Curr. Microbiol. App. Sci. 6(9): xx-xx. doi: https://doi.org/ 10.20546/ijcmas.2017.60 9.xx

Sutar, PP., and Gupta DK. 2007. Mathematical modeling of mass transfer in osmotic dehydration of onion slices. Journal of Food Engineering. 78: 90-97

Worldatlas, 2017. World leaders in jackfruit production. (Accessed 21 $21^{\mathrm{st}}$ March 2019)

https://www.worldatlas.com/articles/worldleaders-in-jackfruit-production.html

\section{How to cite this article:}

Mithun K. and Kaleemullah., S. 2019. Quality Evaluation of Osmosed Jackfruit Bulb Slices. Int.J.Curr.Microbiol.App.Sci. 8(05): 466-472. doi: https://doi.org/10.20546/ijcmas.2019.805.055 